\title{
Biosynthesis of Silver Nanoparticles by Using Papaya Fruit Extract
}

\author{
Alvakonda Narayanamma \\ Synthetic Polymer Laboratory, Department of Polymer Science \& Technology, Sri Krishnadevaraya University, Anantapur-515055, Andhra \\ Pradesh, India
}

\begin{abstract}
Nanotechnology in the latest contest is acquiring its potential due to its capability of changing metals into their nanoparticles. There are few studies on the nanoparticles in plants. Our present research is to investigate on the novel synthesis, of biodegradable silver nanoparticles using fruit extract of papaya. In this green synthesis we used papaya fruit extract which acts as a natural reducing agent to synthesize biodegradable silver nanoparticles by using Acrylamide (AM). The silver nanoparticles were synthesized by reducing $\mathrm{AgNO}_{3}$ with fruit extract from papaya. The hydrogel of fruit extract characteristic color is changed from pale yellow to dark brown by reduction. Characterization of newly synthesized biodegradable silver nanoparticles was analyzed by using $U V$ - visible spectroscopic technique, Fourier transform infrared spectroscopy(FTIR), X-Ray Diffraction (DSC), Thermo gravimetric analysis (TGA), XRD, Scanning electron microscopy (SEM), and Transmission electron microscopy (TEM).In the present study 10 nm size nanoparticles are synthesized. These nanoparticles have antimicrobial applications, especially against Bacillus and Escherichia coli.
\end{abstract}

Keywords: Silver Nanoparticles, Acrylamide(AM), BioSynthesis, Transmission electron microscopy(TEM)

\section{Introduction}

The development of green processes for the synthesis of nanoparticles is evolving into a significant field. In the present scenario, nanomaterials have gained as innovative antimicrobial agents due to their high surface area to volume ratio and the unique chemical and physical properties. Chemical, Physical, and Biological methods these nanoparticles can be synthesized.

Biosynthesis of nanoparticles using microorganisms, enzymes, and extract of the plant have been suggested as environmental friendly alternatives to conventional methods[1].

Metal nanoparticles have potential applications in catalysis, photonics, antimicrobial activity and optics[6],[1213],[23],[27],[39].The biosynthesis of nanoparticles performed using microbial strains, enzymes, metabolites [3],[14] and [21]. Biodegradable polymeric nanoparticles based drug delivery systems[4].

Silver nanoparticles are of between $1 \mathrm{~nm}$ and $100 \mathrm{~nm}$ in size and have gained a lot of future research concern. Biological synthesis of nanoparticles were synthesized by some researchers [5],[7] and testing for antimicrobial activities [17],[5], and[31]. silver nanoparticles are capable of rendering high antifungal efficacy and hence has a great potential in the preparation of drugs used against fungal diseases. Nanosilver is highly toxic to several strains of bacteria including so-called gram-positive bacteria such as Staphylococcus aureus and streptococcus pneumonia and gram negative bacteria including E.coli and Pseudomonas aeruginosin.

In the green process, few researchers used plant leaf extracts as reducing agents for metal nanoparticles, which are costeffective and also utilize ambient condition for reduction reaction [15-16]. Wheat protein isolate-based inorganic biodegradable hydrogels are also used for inactivation of bacteria.

Papaya fruit extract for Ag-nanoparticals synthesis was reported first by [10] and that was the first Ag-nanoparticals synthesis from any plant fruit extract. Synthesis of Agnanoparticals from papaya was also reported by [22] using Callus extract of papaya. The size of spherical Agnanoparticles of 60-80 nm was reported. Later,[11]have demonstrated the synthesis of Ag-nanoparticles which are highly toxic against different multidrug resistant human pathogens using papaya fruit extracts,[22] reported $10 \mathrm{~nm}$ nanoparticle size when papaya fruit extract was used.

Natural polymer component of a biodegradable hydrogel can consist of three dimensional network structures which are biocompatible and biodegradable [20]. In general, biomaterials based hydrogels are developed by using natural and synthetic components (polymers)[18],[20]and[33-35].It consists of inorganic-based ones are particularly promising for inactivation of bacterial applications in materials and engineering science, have generated a lot of interest [15].

Biomaterials based inorganic nanocomposite hydrogels are obtained by embedding various types of metallic nanoparticles: metals, clay, and ceramics in hydrogel matrix. However, the greater attraction in biomedical field is due to the incorporation of natural component/compound in hydrogels because of their biocompatibility, biodegradability, and their non-toxic nature.

The fabricated hydrogels and their nanocomposite hydrogels structural and morphological studies were carried out by using Fourier transform infrared (FTIR) spectroscopy, X-ray diffraction (XRD) and the formation of the $\mathrm{Ag}^{0}$ nanoparticles was confirmed by using UV-vis spectra. The thermal stability, surface morphology, the amount and distribution of $\mathrm{Ag}^{0}$ nanoparticles in Poly (Papaya Fruit Extract-Acrylamide) P(PFE-AM) hydrogels were determined by thermogravimetric analysis (TGA), scanning 


\section{International Journal of Science and Research (IJSR) \\ ISSN (Online): 2319-7064}

Index Copernicus Value (2013): 6.14 | Impact Factor (2014): 5.611

electron microscopy-energy dispersive spectroscopy (SEM) and transmission electron microscopy (TEM).

In the present research, the effect of $\mathrm{Ag}^{0}$ nano particles on the antibacterial activity of the P(PFE-AM) hydrogels was studied. In this investigation, the fabrication of Poly (Papaya Fruit Extract-Acrylamide) $\mathrm{P}(\mathrm{PFE}-\mathrm{AM}) \mathrm{Ag}^{0}$ nanocomposite hydrogels for significant antibacterial applications is presented. Hence, the present work deals with the simple, effective, low-cost biological (green) synthesis of silver nanoparticles using papaya fruit extract. Further, the reduction process was monitored by the UV-visible spectroscopy.

\section{Materials}

Papaya fruit was used to make the aqueous extract. Unripe papaya fruit weighing $10 \mathrm{~g}$ was thoroughly washed in distilled water, whipped slightly with tissue paper, cut into small pieces and crushed into $100 \mathrm{ml}$ distilled water with the help of mortar and pestle. Then the mixture filtered through Whatman Nol filter paper. The filter was further filtered through another Whatman No1 filter paper. Papaya (Papain) Fruit extract (PFE) $-10 \%(\mathrm{w} / \mathrm{w})$ in the Sri Krishnadevaraya University Campus, Acrylamide (AM), N, $\mathrm{N}^{1}$ methylenebisacrylamide (MBA), potassium persulfate (KPS) and $\mathrm{N}, \mathrm{N}, \mathrm{N}^{1}, \mathrm{~N}^{1}$-tetramethylethylenediamine (TMEDA) was purchased from S.D Fine Chemicals (Mumbai, India). Silver nitrate $\mathrm{AgNO}_{3}$ was supplied by Merck (Mumbai, India). All the chemicals were used without further purification. Throughout the experiments, double distilled water was used. The department of Microbiology (Sri Krishnadevaraya University, Anantapur, India) has provided standard cultures of the microorganisms.

\subsection{Preparation of poly (Papaya Fruit Extract- Acrylamide P(PFE-AM) Hydrogels}

Different amounts ( $1 \mathrm{ml}, 2 \mathrm{ml}, 3 \mathrm{ml}$, and $4 \mathrm{ml})$ of papaya fruit extract were taken in a $50 \mathrm{ml}$ beaker. To this solution, $1 \mathrm{~g}$ of $\mathrm{AM}, 1 \mathrm{ml}$ of MBA as crosslinker and $1 \mathrm{ml}$ of $\mathrm{KPS} / 1 \mathrm{ml}$ of TMEDA as redox initiating system, were added. Each mixture was stirred for $30 \mathrm{~min}$ over a magnetic stirrer at 100rpm. The gel matrix formed was carefully transferred into a 1 liter beaker containing $500 \mathrm{ml}$ distilled water and the distilled water was repeatedly changed (for every $5 \mathrm{hrs}$ ) for 2 days in order to remove unreacted products such as monomer, cross-linker, initiator and soluble polymers etc. The P(PFE-AM) hydrogels obtained were allowed to dry at ambient temperature for 2 days. The feed Composition of the gels prepared is presented in Table 1.

\subsection{Fabrication of silver nanocomposite hydrogels}

Briefly, $500 \mathrm{mg}$ of dry hydrogels were equilibrated in double distilled water for $48 \mathrm{~h}$ and the swollen hydrogel species were transferred into a beaker containing $50 \mathrm{ml}$ of $\mathrm{AgNO}_{3}$ $(100.07 \mathrm{mM}(5.1 \mathrm{~g} / 300 \mathrm{ml}))$ aqueous solution and then allowed to equilibrate for $24 \mathrm{~h}$. During this equilibrium stage, the $\mathrm{Ag}^{+}$ions are being exchanged from solution to the $\mathrm{P}(\mathrm{PFE}-\mathrm{AM})$ hydrogel networks. The beaker was left in the refrigerator $\left(4^{0} \mathrm{C}\right)$ for $8 \mathrm{~h}$ in order to reduce the $\mathrm{Ag}^{+}$ions into $\mathrm{Ag}^{0}$ nanoparticles. In this process papaya fruit extract act as self-reducing agent. $\mathrm{The}_{\mathrm{Ag}^{0}}$ nanoparticles in the hydrogel obtained were allowed to dry at ambient temperature and the product was used for further studies. In a similar method, the papaya fruit extract -based hydrogels were prepared by varying the papaya fruit extract concentration.

\subsection{Characterization}

\section{Fourier transform infrared (FTIR) spectroscopy}

FTIR spectrophotometer is used to study the transmission of the hydrogel pattern, $\mathrm{Ag}^{+}$ions incorporation and $\mathrm{Ag}^{0}$ nanoparticles patterns in hydrogel networks. The hydrogels and the $\mathrm{Ag}^{0}$ nano particles-embedded P(PFE-AM) hydrogels were completely dried in the oven (Baheti Enterprises, Hyderabad, India) at $60^{\circ} \mathrm{C}$ for $6 \mathrm{~h}$ before their FTIR experiments. Samples were examined between 500 and $4000 \mathrm{~cm}-1$ on a Bruker IFS 66V FTIR spectrometer (Ettlingen, Germany), using the $\mathrm{KBr}$ disk method.

\section{UV-vis spectrophotometer}

$\mathrm{UV}$-vis spectra of $\mathrm{P}(\mathrm{PFE}-\mathrm{AM}) \mathrm{Ag}^{0}$ nanocomposites hydrogels were recorded on an ELICO SL 164 Model UVvis spectrophotometer (The Elico, Hyderabad, India) from 300 to $550 \mathrm{~nm}$. For this study, $100 \mathrm{mg}$ of P(PFE-AM) $\mathrm{Ag}^{0}$ nanocomposite hydrogels were dispersed in $10 \mathrm{ml}$ of distilled water and allowed to stand for $24 \mathrm{~h}$ in order to extract, as much as possible the $\mathrm{Ag}^{0}$ nanoparticles into aqueous phase and these solutions were recorded for their UV-vis absorption spectra.

\section{Thermal studies}

Thermal analysis (TGA) of the samples were carried out using SDT Q 600 DSC instrument (T.A. Instruments-water LLC, Newcastle, DE 19720, USA), at a heating rate of 10 ${ }^{0} \mathrm{C} / \mathrm{min}$ under a constant nitrogen flow $(100 \mathrm{ml} / \mathrm{min})$.

\section{X-ray diffraction (XRD)}

X-ray diffraction (XRD) method was used to identify the formation of $\mathrm{Ag}^{0}$ nano particles in the P(PFE-AM) hydrogels network. These measurements were carried out on dried and finely grounded samples on a Rikagu diffractometer $(\mathrm{Cu}, \mathrm{K} \alpha$ radiation, $\lambda=0.1546 \mathrm{~nm})$ at $40 \mathrm{kV}$ and $50 \mathrm{~mA}$.

\section{Scanning electron microscopy (SEM)}

Scanning electron microscopy (SEM) analysis of plain $\mathrm{P}$ (PFE-AM) hydrogel and $\mathrm{Ag}^{0}$ nanoparticles impregnated $\mathrm{P}$ (PFE-AM) hydrogels were performed using a JEOL JEM$7500 \mathrm{~F}$ (Tokyo, Japan) operated at an accelerating voltage of $2 \mathrm{kV}$. All the samples were carbon-coated, prior to examination on a field emission scanning electron microscope.

\section{Transmission electron microscopy}

Transmission electron microscope (TEM) (JEM-1200EX, JEOL,Tokyo, Japan) was used for morphological observation. TEM sample was prepared by dispersing two to three drops of finely grinded P(PFE-AM) $\mathrm{Ag}^{0}$ nanocomposite $(1 \mathrm{mg} / 1 \mathrm{ml})$ solution on a $3 \mathrm{~mm}$ copper grid and dried at ambient temperature after removing the excess solution using filter paper.

\section{Volume 4 Issue 11, November 2015}




\section{International Journal of Science and Research (IJSR) \\ ISSN (Online): 2319-7064}

Index Copernicus Value (2013): 6.14 | Impact Factor (2014): 5.611

Swelling studies:

Table 1: Preparationof biodegradable (PFAM)hydrogels feedcompositon

\begin{tabular}{|c|c|c|c|c|c|c|}
\hline $\begin{array}{c}\text { Sample } \\
\text { Code }\end{array}$ & $\begin{array}{c}\text { AM } \\
(\mathrm{gm})\end{array}$ & $\begin{array}{c}\text { PFE } \\
(\mathrm{ml})\end{array}$ & $\begin{array}{c}\text { MBA } \\
(\mathrm{mM})\end{array}$ & $\begin{array}{c}\text { KPS } \\
(\mathrm{mM})\end{array}$ & $\begin{array}{c}\text { TMEDA } \\
(\mathrm{mM})\end{array}$ & $\begin{array}{c}\text { Swelling ratio } \\
\text { of equilibrium } \\
\left(\mathrm{S}_{\mathrm{eq}}\right)\left(\mathrm{S}_{\mathrm{g} / \mathrm{g}}\right)\end{array}$ \\
\hline $\begin{array}{c}\mathrm{P}(\mathrm{PFE}- \\
\mathrm{AM})_{1}\end{array}$ & 1 & 1 & 0.648 & 1.849 & 0.8605 & 9.22275 \\
\hline $\begin{array}{c}\mathrm{P}(\mathrm{PFE}- \\
\mathrm{AM})_{2}\end{array}$ & 1 & 2 & 0.648 & 1.849 & 0.8605 & 31.44673 \\
\hline $\begin{array}{c}\mathrm{P}(\mathrm{PFE}- \\
\mathrm{AM})_{3}\end{array}$ & 1 & 3 & 0.648 & 1.849 & 0.8605 & 44.773 \\
\hline $\begin{array}{c}\mathrm{P}(\mathrm{PFE}- \\
\mathrm{AM})_{4}\end{array}$ & 1 & 4 & 0.648 & 1.849 & 0.8605 & 65.69686 \\
\hline
\end{tabular}

The swelling ratios of hydrogel samples were measured at ambient temperature using a gravimetric method. The dried hydrogels were immersed in a $50 \mathrm{ml}$ beaker containing double distilled water until their weight becomes constant. The hydrogels were then removed from water and their surfaces were blotted with filter paper before being weighed. Furthermore, the swollen hydrogels were treated with $\mathrm{AgNO}_{3}$ via a green process. The swelling ratio or swelling capacity $(\mathrm{Sg} / \mathrm{g})$ of the hydrogels developed and their nanocomposites were calculated using the equation 1 :

$$
\text { Swellingr ratio }:\left(S_{g}\right)=\frac{\left(W_{s}-W_{d}\right)}{W_{d}}
$$

where $\mathrm{W}_{\mathrm{s}}$ and $\mathrm{W}_{\mathrm{d}}$ denote the weight of the swollen hydrogel at equilibrium and the weight of the dry hydrogel, respectively. The data provided is an average value of 4 individual sample readings. The swelling studies are presented in the form of graph in Fig. 2 in the results \& discussion section.

\subsection{Antibacterial Activity}

The antibacterial activity of the $\mathrm{Ag}^{0}$ nanocomposite P (PFEAM) hydrogels, under study, was investigated by disc method, using the standard procedure described elsewhere[33-37]. Nutrient agar medium was prepared by mixing peptone $(5.0 \mathrm{~g})$, beef extract $(3.0 \mathrm{~g})$ and sodium chloride $(\mathrm{NaCl})(5.0 \mathrm{~g})$ in $1000 \mathrm{ml}$ distilled water and the $\mathrm{pH}$ was adjusted to 7.0. Finally, agar $(15.0 \mathrm{~g})$ was added to the solution. The agar medium was sterilized in a conical flask using Autoclave at a pressure of $6.8 \mathrm{~kg}(15 \mathrm{lbs})$ for $30 \mathrm{~min}$. This medium was transferred into sterilized Petri dishes in a laminar air flow chamber (Microfilm Laminar Flow Ultra
Clean Air Unit, India, Mumbai).After solidification of the media, the bacteria (Bacillus and Escherichia coli) $(50 \mu \mathrm{l})$ culture was spread on the solid surface of the media. Over this inoculated Petri dish, one drop of gel solutions $(20 \mathrm{mg}$ $/ 10 \mathrm{ml}$ distilled water) was added using a $10 \mu \mathrm{l}$ tip and the plates were incubated for $48 \mathrm{~h}$ at $37{ }^{\circ} \mathrm{C}$.

\subsection{Biodegradation Characterizations}

Biodegradation study was performed by using the weight loss $(\%)$ method. In this method, the gravimetric study was used by using AR0640 analytical balance (OHAUS Corp., Pine Brook; NJ, USA)

\subsection{Method}

Nutrient agar medium was prepared by using the standard procedure described elsewhere [33-37].The agar medium was sterilized by autoclaving at $121{ }^{0} \mathrm{C}$ for $30 \mathrm{~min}$ at a pressure of $6.8 \mathrm{~kg}(15 \mathrm{lbs})$. An Escherichia coli bacterium was inoculated in this medium and the pure culture was maintained separately in the incubator. Then, to $10 \mathrm{ml}$ of sterilized broth, $0.100 \mathrm{~g}$ each of the samples, i.e. both $\mathrm{P}(\mathrm{PFE}-\mathrm{AM})$ hydrogel and their $\mathrm{Ag}^{0}$ nanocomposites samples were added aseptically in separate test tubes and each tube of samples was supplemented with inoculums of the bacterial strains separately. The degradation of samples by E. coli was monitored at time intervals of $1,8,15$ and 30 days. After the required time period, samples were washed repeatedly with deionized water, oven-dried at $40 \pm 1{ }^{\circ} \mathrm{C}$ for $24 \mathrm{~h}$. Then, the samples were weighed to determine the weight loss. The ratio of weight remained $(\mathrm{Wr})$ was calculated based on Eq.2:

$$
W_{r}=\frac{W_{d}}{W_{0}}
$$

Where $W_{\mathrm{o}}$ is the initial weight of the dried gel sample and $W_{\mathrm{d}}$ is the weight of the dried sample after degradation at a given time.

\section{Results and Discussion}

The synthetic procedure of $\mathrm{Ag}^{0}$ nanocomposite $\mathrm{P}(\mathrm{PFE}-\mathrm{AM})$ hydrogels consists of the following three steps, as shown, schematically, in Scheme 1: (i) the fabrication of P(PFEAM) hydrogels via free-radical reaction; (ii) the addition of $\mathrm{Ag}^{+}$ions-loaded hydrogels via swelling method and (iii) the formation of $\mathrm{Ag}^{0}$ nanocomposite P(PFE-AM) hydrogels via green process (The $\mathrm{Ag}^{0}$ nanoparticles were prepared by reducing $\mathrm{AgNO}_{3}$ with self- reduction in the $\mathrm{P}(\mathrm{PFE}-\mathrm{AM})$ hydrogels network) 


\section{International Journal of Science and Research (IJSR)
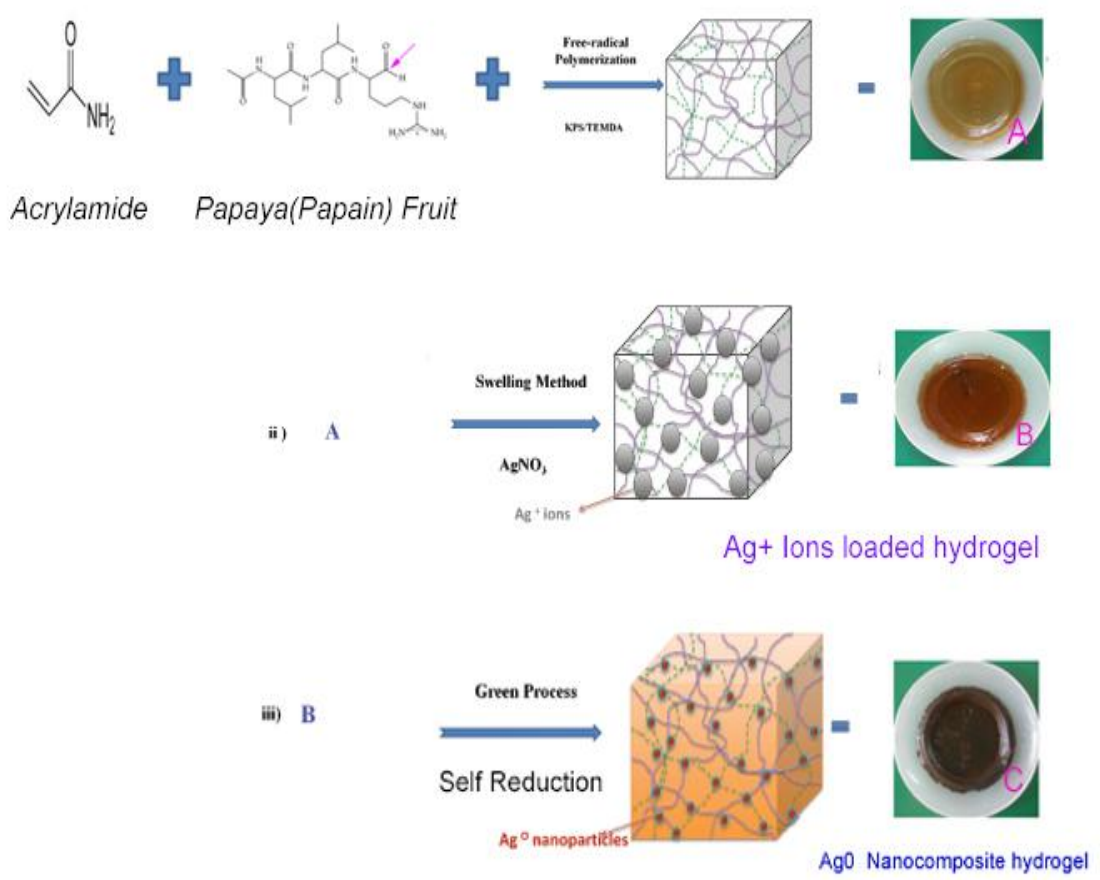

Scheme1: The synthetic procedure of $\mathrm{Ag}^{0}$ nanocomposite P(PFE-AM) hydrogels consists of the following three steps, as shown, schematically (i) the fabrication of P(PFE-AM) hydrogels via free-radical reaction; (ii) the addition of $\mathrm{Ag}^{+}$ ions-loaded hydrogels via swelling method and (iii) the formation of $\mathrm{Ag}^{0}$ nanocomposite P(PFE-AM) hydrogels via green process ( $\mathrm{The} \mathrm{Ag}^{0}$ nanoparticles were prepared by reducing $\mathrm{AgNO}_{3}$ with self reduction in the P(PFE-AM) hydrogels network

\subsection{Fourier transform infrared (FTIR) spectroscopy analysis:}

The evidence for the successful preparation of $\mathrm{Ag}^{0}$ nanocomposite hydrogel was analyzed by FTIR spectral comparison, as shown in Fig. 1A. The spectrum of P(PFE$\mathrm{AM}$ ) sheets shows a broad absorption band at $3424 \mathrm{~cm}^{-1}$ that is related to the $\mathrm{NH}$ asymmetric symmetric stretching vibrations groups, band at $2354 \mathrm{~cm}^{-1}$ are attributed to stretching vibrations of $\mathrm{CH}_{3}$ units and an absorption band at $1615 \mathrm{~cm}^{-1}$ from the carbonyl groups of P(PFE-AM) hydrogel[28]. These peaks have shifted to 3444,2342 and $1604 \mathrm{~cm}^{-1}$ in $\mathrm{Ag}^{0}$ nanocomposite P(PFE-AM). As a result, it can be concluded that $\mathrm{Ag}^{0}$ nanoparticles are present in P(PFE-AM) hydrogels.

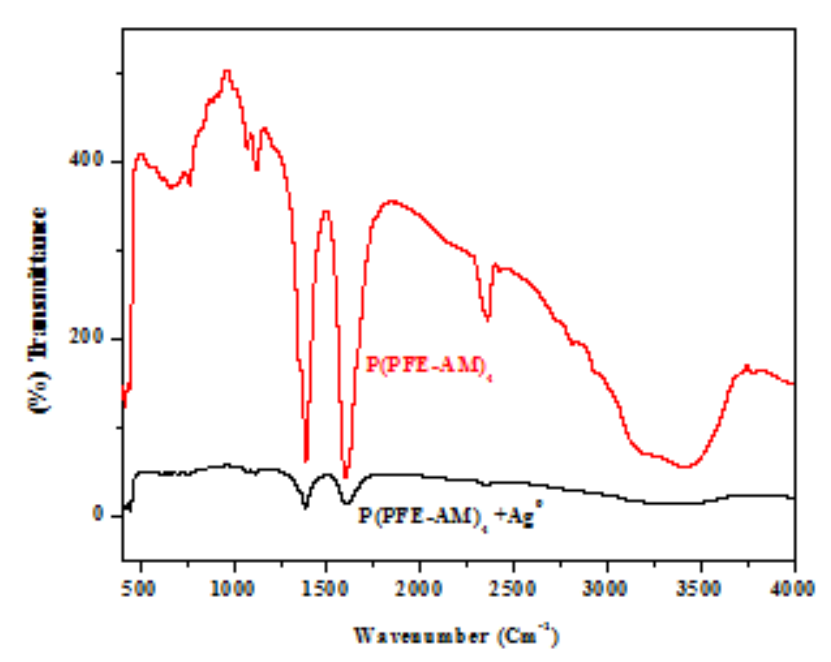

Figure 3: FTIR spectra of pure $\mathrm{P}(\mathrm{PFE}-\mathrm{AM})_{4}$ hydrogel and $\mathrm{P}(\mathrm{PFE}-\mathrm{AM})_{4}+\mathrm{Ag}^{0}$ nanocomposite biodegradable hydrogels

\subsection{UV-Visible Analysis}

To prove the formation of the $\mathrm{Ag}^{0}$ nanoparticles in the hydrogel networks the UV-Vis spectra was used. Fig.2 shows the absorption characteristics of the Pure PFE \& their $\mathrm{P}(\mathrm{PFE}-\mathrm{AM}) \mathrm{Ag}^{0}$ nanocomposite hydrogel. The characteristic plasmonic-resonance peak of $\mathrm{Ag}^{0}$ nanoparticles was observed at $\lambda_{\max } 430.50 \mathrm{~nm}$ showing the absorption spectra of which measured after 5 hours and the absorbance peak observed at $430.50 \mathrm{~nm}$, broadening of peak indicated that the particles are polydispersed.However, no intense peak around 430.50nm was observed in P(PFE-AM) $\mathrm{Ag}^{0}$ hydrogel. This clearly indicates the formation of silver nanoparticles in $\mathrm{P}(\mathrm{PFE}-\mathrm{AM})$ hydrogel and their dispersion. 


\section{International Journal of Science and Research (IJSR) \\ ISSN (Online): 2319-7064}

Index Copernicus Value (2013): 6.14 | Impact Factor (2014): 5.611

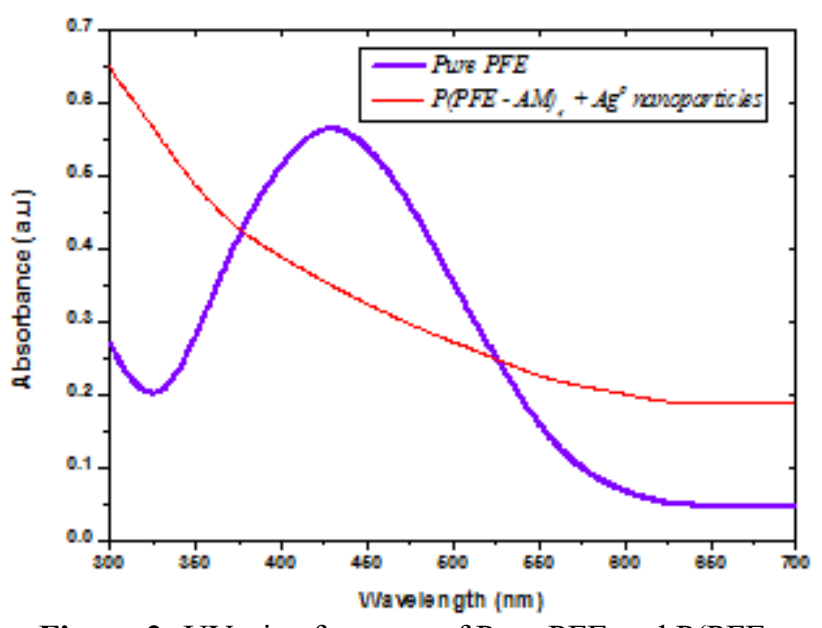

Figure 2: UV-vis of spectra of Pure PFE and P(PFE-

$$
\mathrm{AM})_{4}+\mathrm{Ag}^{0}
$$

\subsection{Thermo gravimetric analysis (TGA)}

Thermogravimetric analysis (TGA) was used to study the formation of $\mathrm{Ag}^{0}$ nano particles in the hydrogel network. The primary thermogram of the hydrogel and the nanocomposite hydrogel are shown in Fig.3. The thermal decomposition of $\mathrm{P}(\mathrm{PFE}-\mathrm{AM})$ hydrogel occurred at $500^{\circ} \mathrm{C}$ with a significant weight loss $(83 \%)$, but for the $\mathrm{Ag}^{0}$ nanocomposite hydrogel a comparatively very low weight loss $(58.8 \%)$ was found at $500^{\circ} \mathrm{C}$, which is due to the incomplete decomposition of the $\mathrm{Ag}^{0}$ nanoparticles. Moreover, according to the TGA results, the $\mathrm{Ag}^{0}$ nanocomposite hydrogels showed a higher thermal stability than the $\mathrm{P}(\mathrm{PFE}-\mathrm{AM})$ hydrogel. The difference in is $24.2 \%$ and it confirms the presence of $\mathrm{Ag}^{0}$ nano particles (by weight loss) in the hydrogel.

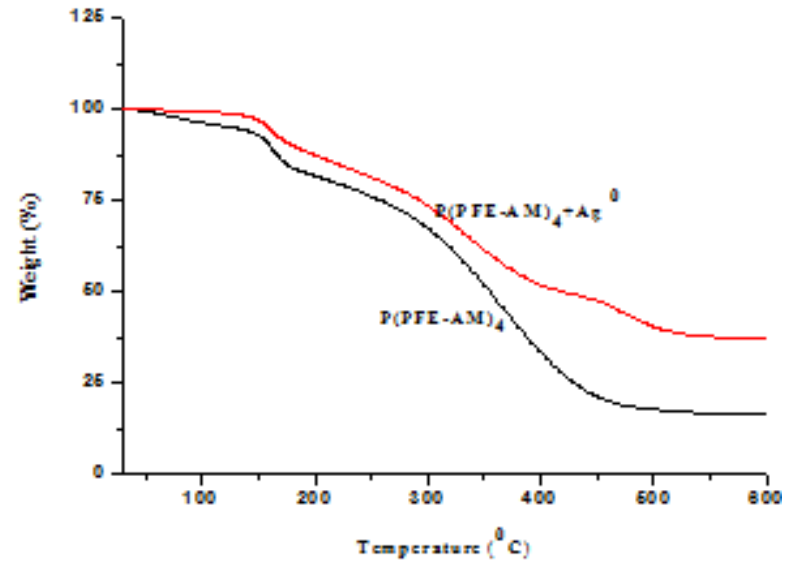

Figure 3: TGA curves of pure $\mathrm{P}(\mathrm{PFE}-\mathrm{AM})_{4}$ and $\mathrm{P}(\mathrm{PFE}-$ $\mathrm{AM})_{4}+\mathrm{Ag}^{0}$ nanocomposite hydrogels

\subsection{X-ray diffraction (XRD) Analysis}

The X-ray diffraction is a suitable technique to identify the crystallinity of the inorganic particles present in the hydrogels and hence the chemical composition of the material under investigation can be obtained. Fig.4 shows the XRD pattern of P(PFE-AM) hydrogel stabilized $\mathrm{Ag}^{0}$ nano particles, synthesized via a gas-solution process at room temperature. In Fig. 4 the insert figure shows the XRD pattern of pure $\mathrm{P}(\mathrm{PFF}-\mathrm{AM})$ which exhibits strong and broad diffraction peaks at $2 \theta=24.9$ and 41.30 . The four other characteristic peaks showed in the case of $\mathrm{Ag}^{0}$ nanocomposite hydrogel indicates the face-centered cubic (fcc) structure. The diffraction peaks at $2 \theta=38.9,44.62,64.9$ and 77.53 corresponding to the reflections of crystal planes (1 111$),\left(\begin{array}{lll}2 & 0 & 0\end{array}\right),\left(\begin{array}{lll}2 & 2 & 0\end{array}\right)$ and (3 1 1) respectively. This face- centered cubic (fcc) structure indicates that $\mathrm{Ag}^{0}$ nanoparticles were dispersed in the $\mathrm{P}(\mathrm{PFF}-\mathrm{AM})$ hydrogels network

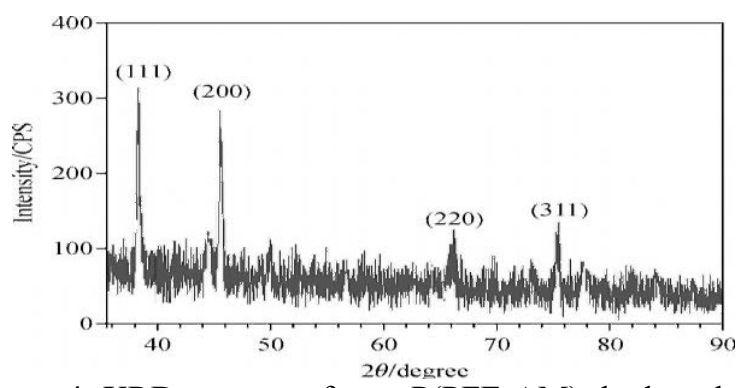

Figure 4: $\mathrm{XRD}$ patterns of pure $\mathrm{P}(\mathrm{PFE}-\mathrm{AM})_{4}$ hydrogel and $\mathrm{P}(\mathrm{PFE}-\mathrm{AM})_{4} \mathrm{Ag}^{0}$ nanocomposite biodegradable hydrogels

\subsection{Scanning Electron Microscopy}

The surface morphology of P(PFE-AM) and $\mathrm{Ag}^{0}$ nanocomposite hydrogels were investigated with SEM. Fig.5(A) shows the SEM micrographs of the P(PFE-AM) and Fig.5(B) shows $\mathrm{Ag}^{0}$ nanocomposite hydrogels. It indicates a clear rough morphology for the pure P(PFE-AM) hydrogel, Fig.5(A) whereas $\mathrm{Ag}^{0}$ nanoparticles loaded P(PFE-AM) hydrogel as shown in Fig.5(B) exhibited smaller nano particles distributed throughout the gel matrix having porous in nature which is in conformity with the UVVis spectra because PFE slightly escaped from the hydrogels as it can be seen in Fig.5(C).It is worth mentioning from the SEM analysis that no individual silver nanoparticles were observed outside the $\mathrm{P}(\mathrm{PFE}-\mathrm{AM})$ hydrogels, indicating a strong interaction between the P(PFE-AM) and the $\mathrm{Ag}^{0}$ particles. In order to further confirm the presence of $\mathrm{Ag}^{0}$ nanoparticles in the P(PFE-AM) hydrogel and to determine the identity of the $\mathrm{Ag}^{0}$ nanoparticles.

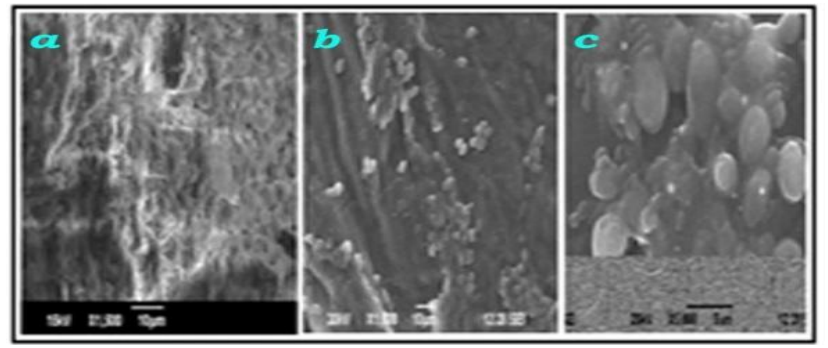

Figure 5: $\mathrm{SEM}$ images of pure $\mathrm{P}(\mathrm{PFE}-\mathrm{AM})_{4}, \mathrm{P}(\mathrm{PFE}-$ $\mathrm{AM})_{4}+\mathrm{Ag}^{+}$and $\mathrm{P}(\mathrm{PFE}-\mathrm{AM})_{4}+\mathrm{Ag}^{0}$ nanocomposite hydrogels

\subsection{Transmission electron microscopy (TEM) analysis}

TEM analysis also confirmed the formation of spherical $\mathrm{Ag}^{0}$ nanoparticles in the $\mathrm{P}(\mathrm{PFE}-\mathrm{AM})$ hydrogels network. The TEM image is shown in Fig.6 The average size of the nanoparticles was found to be about $\square 10 \mathrm{~nm}$. It is evident that $\mathrm{Ag}^{0}$ nanoparticles were highly stabilized by using PFE in the hydrogel network. These results are mainly due to the strong interaction between the $\mathrm{Ag}^{0}$ nanoparticles and P(PFE$\mathrm{AM})_{4}$ 


\section{International Journal of Science and Research (IJSR) \\ ISSN (Online): 2319-7064}

Index Copernicus Value (2013): 6.14 | Impact Factor (2014): 5.611

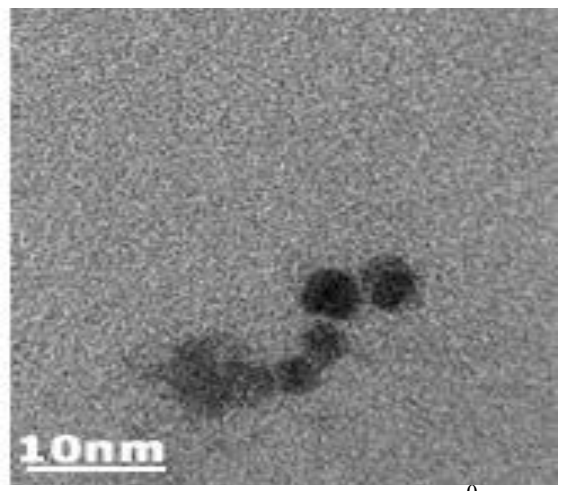

Figure 6: TEM images of $\mathrm{P}(\mathrm{PFE}-\mathrm{AM})_{4}+\mathrm{Ag}^{0}$ nanocomposite hydrogel

\subsection{Swelling Properties}

The result present in Fig. 7 indicates that the $\mathrm{Ag}^{0}$ nanocomposite hydrogels have a superior swelling ratio, when compared to the blank P(PFE-AM) hydrogels. The reason for this is that when $\mathrm{Ag}^{+}$ions-loaded hydrogels were reduced by self-reduction, the many $\mathrm{Ag}^{+}$ions present in the hydrogels led to the formation of silver nanoparticles within the hydrogel, which expanded the gel networks and promoted higher water molecules uptake capacity. This interesting phenomenon can play a significant role in biomedical applications, particularly in antibacterial applications. Based on this characteristic, (Varaprasad et al., 2011) have prepared different type of hydrogels for drug delivery and antibacterial applications.

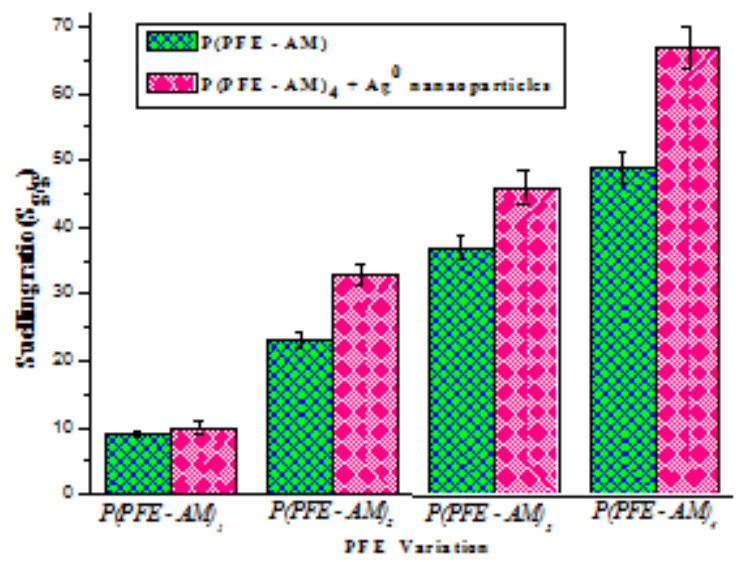

Figure 7: Swelling behavior of $\mathrm{P}(\mathrm{PFE}-\mathrm{AM})$ varied hydrogels and $\mathrm{Ag}^{0}$ nanocomposite

\subsection{Antibacterial Activity}

$\mathrm{Ag}^{0}$ nanoparticles are well thought-out environmentally ecofriendly and nontoxic antibacterial activity material, but the main disadvantage is their poor binding characteristic and stability, which restrict their utility. Therefore, polymers stabilized nanoparticles (Raghavendra, G M., Jayaramudu et al.,) and nanoparticles embedded in hydrogel networks (Jayaramudu, T., Raghavendra, G. M et al.,2013) are outstanding approaches for antibacterial applications (Jayaramudu, T., Raghavendra, G. M et al.,2013). The antibacterial abilities of P(PFE-AM) and $\mathrm{Ag}^{0}$ nanoparticles contained hydrogels were investigated by calculating their capacity to inhibit the zone of bacillus and E. coli growth on agar culture dishes. After $48 \mathrm{~h}$ of incubation at $37{ }^{\circ} \mathrm{C}$, there was the inactivation of bacterial zones and no bacterial colonies were clearly observed (Fig. 8) in the Petri dishes. The diameter of the inhibition zone for the $\mathrm{Ag}^{0}$ nanocomposite $\mathrm{P}(\mathrm{PFE}-\mathrm{AM})$ hydrogel is as follows: (Fig. 8 I(A ) $(1.5 \mathrm{~cm})$ and $\mathrm{II}(\mathrm{A})(1.2 \mathrm{~cm}))$, whereas for the pure P(PFE-AM) hydrogels (Fig. $8 \mathrm{I}$ (B) $0.0 \mathrm{~cm}$ and II(B) $0.0 \mathrm{~cm}$ ), it showed no inhibition ability. Therefore, PFE in combination with $\mathrm{Ag}^{0}$ nanocomposites hydrogels exhibited excellent antibacterial activity.
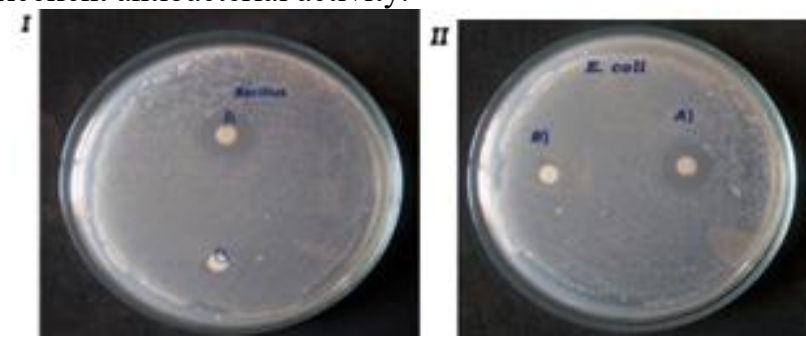

Figure 8: Antibacterial activity of $\mathrm{I}(\mathrm{B})$ plain $\mathrm{P}(\mathrm{PFE}-\mathrm{AM})_{4}$, I(A) $\mathrm{P}(\mathrm{PFE}-\mathrm{AM})_{4}+\mathrm{Ag}^{0}$ nanocomposite hydrogels on Bacillus and II(B) plain $\mathrm{P}(\mathrm{PFE}-\mathrm{AM})_{4} \mathrm{II}(\mathrm{A}) \mathrm{P}(\mathrm{PFE}-$ $\mathrm{AM})_{4}+\mathrm{Ag}^{0}$ nanocomposite hydrogels on E.coli

\subsection{Biodegradation studies}

The biodegradation property of pure $P(P F E-A M)$ hydrogel and $\mathrm{Ag}^{0}$ nanocomposite hydrogel developed, were carried out by weight loss methods. The degradation behaviors of $P(P F E-A M)$ hydrogel and $\mathrm{Ag}^{0}$ nanocomposites hydrogel are shown in Fig.9. From the figure, it is observed that pure $P(P F E-A M)$ hydrogel shows high weight loss (\%) than $P(P F E-A M) \mathrm{Ag}^{0}$ nanocomposite hydrogels. This is due to the fact that $\mathrm{Ag}^{0}$ nano particles that escape from the hydrogel in aqueous medium got attached to the negatively charged bacterial cell wall, which causes cell death to the bacteria. Therefore, cells metabolic activity is reduced (degradation also less). But this is not the case for pure $P(P F E-A M)$ hydrogel which does not have inorganic $\mathrm{Ag}^{0}$ nano particles. Therefore, it readily undergoes degradation when compared to $\mathrm{Ag}^{0}$ nanocomposites.

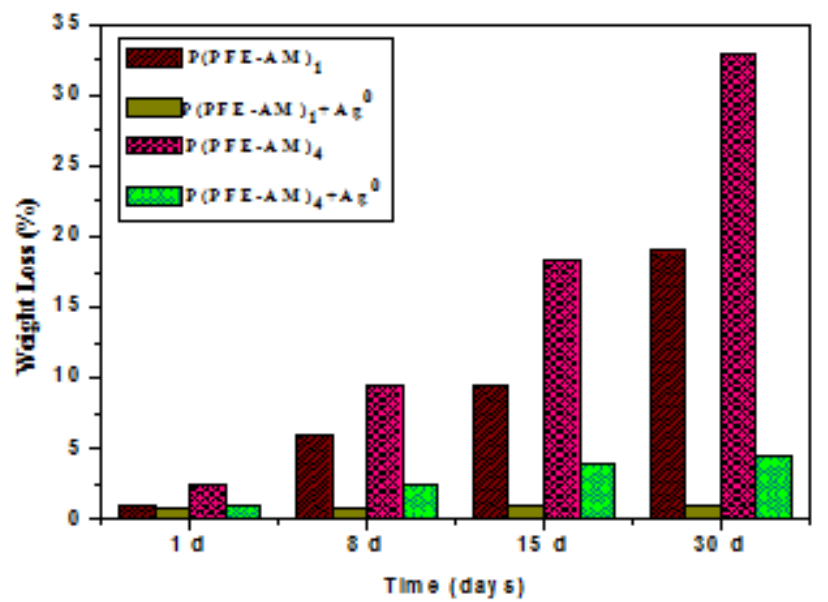

Figure 9: Biodegradation of PFE-hydrogels(P(PFE$\mathrm{AM})_{1}$ and $\left.\mathrm{P}(\mathrm{PFE}-\mathrm{AM})_{4}\right)$ and $\mathrm{Ag}^{0}$ nanocomposite $(\mathrm{P}(\mathrm{PFE}-$ $\mathrm{AM})_{1}+\mathrm{Ag}^{0}$ and $\left.\mathrm{P}(\mathrm{PFE}-\mathrm{AM})_{4}+\mathrm{Ag}^{0}\right)$ hydrogels by E.coli.

\section{Conclusion}

An effective green process for the fabrication of a novel biodegradable silver nanocomposite hydrogel with papaya

\section{Volume 4 Issue 11, November 2015}




\section{International Journal of Science and Research (IJSR) \\ ISSN (Online): 2319-7064}

Index Copernicus Value (2013): 6.14 | Impact Factor (2014): 5.611

fruit extract as a stabilizing agent for the silver nanoparticles has been described. The $\mathrm{Ag}^{0}$ nanoparticles were prepared by reducing $\mathrm{AgNO}_{3}$ with papaya fruit extract. These composites were developed and characterized by spectral, thermal and electron microscopy. In our study, it is found that nanoparticles obtained were sized $\square 10 \mathrm{~nm}$. The synthesis of silver nanoparticles were confirmed by the change of

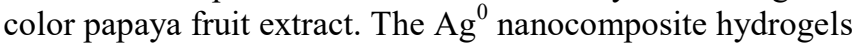
prepared have significant antibacterial activity against Bacillus and E. coli. Toxicity studies of silver nanoparticles on human pathogen opens a door for a new range of antibacterial agents. Applications of such eco-friendly nanoparticles in bactericidal, wound healing and other medical and electronic applications, makes this method potentially exciting for the large-scale synthesis of other nanomaterials.

\section{References}

[1] Ahmad, A., Senapati, S., Khan, M.I., Kumar, R. and Sastry, M. 2005. Extra intracellular biosynthesis of gold nanoparticles by an alkali tolerant fungus, Trichothecium sp. J. Biomed. Nanotechnol. 1: 47-53.

[2] Ahmad, A., Senapati, S., Khan, M.I., Kumar, R. and Sastry, M. 2004. Extracellular biosynthesis of monodisperse gold nanoparticles by a novel extremophilic actinomycete, Thermomonaspora $s p$. Langmuir. 19: 3550-3553.

[3] Ali.D.M.,Sasikala,M.,Gunasekara, M.,Thajuddin, N.,(2011), Biosynthesis and characterization of silver nanoparticles using marine cyanobacterium,oscillatoriawillei ntdm01.Digest J.Nanometer.Biostruct.6(2),385-390.

[4] Avnesh, K., Sudesh, K.Y., Subhash, C.Y., (2010), Biodegradable polymeric nanoparticles based drug delivery systems. Colloids Surf., B 75, 1-18.

[5] Bhyan et.al.,(2007).Biological synthesis of nanoparticles by plant extracts is at present under exploitation as some researchers worked on it.

[6] Biswas, K., Chattopadhyay, I., Ranajit, K. B., \& Uday, B. Biological activities and medicinal properties of neem (Azadirachta indica). Current Science, 82,(2004), 1336-1345.

[7] Calvo.et.al.,(2006), Biological synthesis of nanoparticles by plant extracts is at present under explotation as some researchers worked on it and testing for antimicrobial activities.

[8] Chunhua, L., Xiupei, Y., Hongyan, Y., Zaidi, Z., \& Dan, X. Preparation of Silver Nanoparticle and Its Application to the Determination of it-DNA. Sensors, 7, (2007), 708-718.

[9] Cobley, C. M., Skrabalak, S. E., Campbell, D. J., Xia, Y. Plasmonics (2009) 4,171 .

[10] Devendra J, Hemant KD, Sumita K, Kothari SL. Synthesis of plant-mediated Silver nanoparticles using Papaya fruit extract and evaluation of their anti microbial activities. Digest J Nanomater Biostruct 2009; 4(4):723-7.

[11]Farooqui M, Hashmi S, Shaikh Z. Papaya fruit extract: a potent source for synthesis of bionanoparticle. J Environ Res Dev( 2013);7(4A):1518-22.
[12] Govindraju, K., Kiruthiga, V. and Singaravelu, G. (2008). Evaluation of biosynthesized silver nanoparticles against fungal pathogens of mulberry Morus indica. Journal of Biopesticides, 1: 101-104.

[13] Govindraju, K., Kiruthiga, V., Ganesh Kumar, V. and Singaravelu, G. (2009). Extracellular synthesis of silver nanoparticles by a marine alga, Sargassum wightii Grevilli and their antibacterial effects. Journal of Nanoscience and Nanotechnology, 9: 5497-5501.

[14] Harekrishna,B.,Dipak,K.B.Gobinda,P.S.Priyanka,S.,San kar,P.D.,Ajay,M.,2009.Green synthesis of silver nanoparticles using latex of Jatrophacurcas.Coll.Suff.,A:Physicochem.Engg.Aspects 339, 134-139

[15] Jayaramudu, T., Raghavendra, G. M., Varaprasad, K., Sadiku, R., Ramam, K., \& Raju, K. M. IotaCarrageenan-based biodegradable $\mathrm{Ag}^{0}$ nanocomposite hydrogels for the inactivation of bacteria, Carbohydrate Polymers, 95, (2013), 188- 194.

[16] Jayaramudua, T., Raghavendra, G. M., Varaprasad, K., Sadiku, R. \& Mohana Raju, K. Development of novel biodegradable $\mathrm{Au}$ nanocomposite hydrogels based on wheat: For inactivation of bacteria. Carbohydrate Polymers, 92, (2013), 2193- 2200.

[17] Khandelwal, N., Singh, A., Jain, D., Upadhyay, M.K. and Verma, H.N. (2010). Green synthesis of silver nanoparticles using Argemone Mexicana leaf extract and Evaluation of their antimicrobial activities. Digest $\mathrm{J}$ Nanomater Biostruct, 5: 483-489.

[18] Murali Mohan, Y., Vimala, K., Varsha, T., Varaprasad, K., Sreedhar, B., Bajpai, S. K., \& Mohana Raju K. Controlling of silver nanoparticles structure by hydrogel networks. Journal of Colloid and Interface Science, 342, (2010), 73-82.

[19] Murphy, C.J. (2008) Sustainability as an emerging design criteria in nanoparticles synthesis, J. Master Chem 18(1) 2173-2176.

[20] Murthy, P.S.K., Murali Mohan, Y., Varaprasad, K., Sreedhar, B. \& Mohana Raju, K. First successful design of semi-IPN hydrogel-silver nanocomposites: A facile approach for antibacterial application. Journal of Colloid and Interface Science, 318, (2008), 217-224.

[21] Nagati, V., Rama, K., Jahnavi, A., Manisha, R.D., Karunakar, R.K., Rudra, P.M.P., 2012. Green synthesis and characterization of SILVER nanoparticles from Cajanus cajan leaf extract and its antibacterial activity. Int. J. Nanomater. Biostructures 2 (3), 39- 43.

[22] Namrata M, Avinash I, Aniket G, Mahendra R. Synthesis of silver nanoparticles using callus extract of carica papaya-a first report. Plant Biochem Biotechnol 2009; 18(1):83-6.

[23]]Nie, S. and Emory, S.R. (1997). Probing single molecules and single nanoparticles by surface-enhanced Raman Scattering. Science, 275: 1102-1106.

[24] Raghavendra, G M., Jayaramudua, T., Varaprasad, K., Sadiku, R., Sinha Ray, S., and Mohana Raju K.Cellulose-polymer-Ag nanocomposite fibers for antibacterial fabrics/skin scaffolds. Carbohydrate Polymers, 93, (2013), 553-560

[25] Raveendran, P., Fu, J. and Wallen, S.L. (2006). A simple and , green ${ }^{\text {ece }}$ method for the synthesis of $\mathrm{Au}$, $\mathrm{Ag}$, and $\mathrm{Au}-\mathrm{Ag}$ alloy nanoparticles. Green Chem, 8: 34 38 . 


\section{International Journal of Science and Research (IJSR) \\ ISSN (Online): 2319-7064}

Index Copernicus Value (2013): 6.14 | Impact Factor (2014): 5.611

[26] Saxena, A., Tripathi, R.M. and Singh, R.P. (2010). Biological Synthesis of silver nanoparticles by using Onion (Allium cepa) extract and their antibacterial activity. Digest J Nanomater Biostruct, 5: 427-432.

[27] Shipway, A.N, and Willner, I. (2001). Nanoparticles as structural and functional units in surface confined architectures. Chemical Communication, 20: 20352045.

[28] Soleimani, F., Sadeghi, M., \& Shahsavari, H. (2012). Preparation and swelling behavior of carrageenan-graftpolymethacrylamide superabsorbent hydrogel as a releasing drug system. Indian Journal of Science and Technology, 5, 2143-2147.

[29] Sun, L. F., Zhuo, R. X., \& Liu, Z. L. Studies on the synthesis and properties of temperature responsive and biodegradable hydrogels. Macromolecular Bioscience, 3, (2003), 725-728.

[30] Thirumurgan, A., Tomy, N.A., Jai Ganesh, R. and Gobikrishnan, S. (2010). Biological reduction of silver nanoparticles using plant leaf extracts and its effect an increased antimicrobial activity against the clinically isolated organism. De Pharm Chem, 2: 279-284.

[31] Thirumurgan.A,Tony.N.AJai Ganesh. R and Gopikrishnan.S.Dehar Chem (2010),279-284.

[32] Tiwari, A., Grailer J. J., Pilla, S., Steeber, D. A., \& Gong, S. Biodegradable hydrogels based on novel photopolymerizable guar gum-methacrylate macromonomers for in situ fabrication of tissue engineering scaffolds. Acta Biomaterialia, 5, (2009), 3441-3452.

[33] Varaprasad, K., Murali Mohan, Y., Ravindra, S., Narayana Reddy, N., Vimala, K., Monika, K., Sreedhar, B. \& Mohana Raju, K. Hydrogel-silver nanoparticle composites: A new generation of antimicrobials. Journal of Applied Polymer Science, 115, (2010), 119-1207.

[34] Varaprasad, K., Murali Mohan, Y., Vimala, K., \& Mohana Raju K. Synthesis and characterization of hydrogel-silver nanoparticle-curcumin composites for wound dressing and antibacterial application. Journal of Applied Polymer Science, 121, (2011), 784-796.

[35] Varaprasad, K., Narayana Reddy, N., Ravindra, S., Vimala, K., \& Mohana Raju, K. Synthesis and characterizations of macroporous poly(acrylamide- 2acrylamido-2-methyl-1-propanesulfonic acid) hydrogels for in vitro drug release of ranitidine hydrochloride. International Journal of Polymeric Materials, 60, (2011), 490-503.

[36] Varaprasad, K., Vimala, K., Ravindra, S., Narayana Reddy, N., \& Mohana Raju, K. Development of sodium carboxymethyl cellulose-based poly (acrylamide-co2acrylamido-2-methyl-1-propane sulfonic acid) hydrogels for in vitro drug release studies of ranitidine hydrochloride an anti-ulcer drug. Polymer - Plastics Technology and Engineering, 50(12), (2011), 11991207.

[37] Varaprasad, K., Vimala, K., Ravindra, S., Narayana Reddy, N., Siva Mohana Reddy, G., \& Mohana Raju, K. Biodegradable chitosan hydrogels for in vitro drug release studies of 5-flurouracil an anticancer drug. Journal of Polymers and the Environment, 20, (2012), $573-582$.
[38] Virender, K. S., Ria, A.Y. and Yekaterina, L. (2009). "Silver nanoparticles Green Synthesis and their antimicrobial activities". J. Mat. Sci, 9: 83-96.

[39] Wang, H., \& Helliwell, K. Epimerization of catechins in green tea infusions. Food Chemistry, 70, (2000), 337-344.

[40] Wang, R., Zhou, W., \& Jiang, X. Reaction kinetics of degradation and epimerization of epigallocatechin gallate (EGCG) in an aqueous system over a wide temperature range. Journal of Agricultural and Food Chemistry, 56,(2004), 2694-2701. 